об отличиях старшего и младшего подросткового возраста. Теоретические и эмпирические данные могут быть использованы для улучшения процесса обучения и воспитания подрастающего поколения.

1. Выготский, Л. С. Детская психология [Текст] : учеб.пособие для студ. высших учеб. заведений / Л. С. Выготский. - Москва :Таус, 1984. - 213 с.

2. Голубь, О. В Я-концепция как экзистенциальное ядро личности, обеспечивающее ее внутреннюю самоорганизацию и саморегуляцию [Электронный ресурс] / О. В. Голубь. - Режим доступа: https://elibrary.ru/item.asp?id=21093753.

3. Круглова, Т. Е. Особенности эмоциональной сферы подростков с разной успеваемостью [Электронный ресурс] / Т. Е. Круглова // Молодой ученый №9 - 2017. - Режим доступа: https://moluch.ru/archive/143/40260/.

4. Мухина, В. С. Возрастная психология. Хрестоматия [Текст] / В. С. Мухина, А. А. Хвостов Санкт-Петербург : Азбука, 2001. - 350 с.

5. Нухова, М. В Сборник научных статей очной Международной молодежной научно-практической конференции «Образование и человек в условиях социальных изменений» [Текст] / М. В. Нухова, А. А. Хвостова - Москва : ЭКСМО, 2017. - 3 с.

\title{
Соловей В.Д., Алонцева.А.И. \\ Изучение личностных особенностей студентов социономических и технических направлений профессиональной подготовки
}

Новокузнеикий филиал институт Кемеровского государственного университета (Россия, Новокузнеик)

doi 10.18411/spc-04-03-2018-29

idsp 000001:spc-04-03-2018-29

В современном обществе актуально и остро встает проблема психологической помощи людям в выборе профессии. Выбор профессии - это не одномоментный акт, а процесс, состоящий из ряда этапов, продолжительность которого зависит от внешних условий и индивидуальных особенностей субъекта выбора профессии. Выбор профессии осложняется ещё и тем, что профориентация в современных условиях всё ещё не достигает своих главных целей - формирование у учащихся профессионального самоопределения, соответствующего индивидуальным особенностям каждой личности и запросам общества в кадрах, его требованиям к современному работнику. Существенным препятствием развития профориентации является то, что она, как правило, рассчитана на некоторого усреднённого ученика; отсутствует индивидуальный, дифференцированный подход к личности выбирающего профессию; используются в основном словесные, декларированные методы, без представления возможности каждому попробовать себя в различных видах деятельности, в том числе и в избираемой.Человеку необходимо обладать не только определенным объемом профессиональных знаний, умений, навыков, но и комплексом личностных особенностей, которые обуславливают успешность осуществления его деятельности. В данной работе будут рассмотрены студенты технических и социономических направлений профессиональной подготовки, для того, чтобы понять правильно ли они выбрали профессиональную направленность.

Объект: личностные особенности.

Предмет: личностные особенности студентовсоциономических и технических направлений профессиональной подготовки.

Цель: изучение личностных особенностей студентов социономических и технических направлений профессиональной подготовки.

Методологические принципы исследования: научности, детерминизма 
Методы исследования: теоретический анализ литературы, психодиагностическое тестирование, математически-статистический метод обработки данных (t-критерий Стьюдента).

Методики исследования:

1. Личностный опросник(Г. Айзенк ).

2. Самоактуализационный тест (Э. Шострома).

3. Методика Опросник профессиональной готовности (Л. Н. Кабардовой).

Практическая значимость исследования: заключается в возможности формирования рекомендаций для выбора студентами направления профессиональной подготовки, подходящее их личностным особенностям, вследствие чего после обучения они смогут успешно работать по освоенной ими профессии.

Ключевые слова: студенты социономических направлений, студенты технических направлений, личностные особенности, профессиональное самоопределение.

Задачи исследования:

1. Ознакомиться сличностными особенностями человека в зарубежной и отечественной литературе.

2. Изучить психологические характеристики студентов социономических и технических направлений профессиональной подготовки.

3. Рассмотреть проблемы профориентационного самоопределения, как научную категорию.

4. Описать выборку и этапы исследования.

5. Подобрать методы и методики исследования.

6. Провести диагностику личностных особенностей студентов.

7. Произвести сравнительный анализ личностных особенностей студентов социономических и технических направлений профессиональной подготовки.

Гипотеза: личностные особенности у студентов социономических и технических направлений профессиональной подготовки имеют различия.

Выявление личностных особенностей у студентов социономических и технических направлений профессиональной подготовки, происходило с помощью следующих методов, метода изучения психологической литературы, психодиагностическое тестирование, математико-статистический метод обработки данных (критерийStudent). А так же с помощью трёх методик: Подростковый опросник (Г. Айзенка); Самоактуализационный тест (Э. Шостром); Методика определения профессиональной готовности (Л. Н. Кабордовой).

\section{Методы:}

1) Теоретический анализ литературы

Данный метод заключается в исследовании психологической литературы отечественных (Б. Г. Ананьев, Л. С. Выготский) и зарубежных авторов. С помощью данного метода можно выделить наиболее встречающиеся личностные особенности у студентов социономических и технических направлений профессиональной подготовки.

Теоретический анализ литературы позволяет более глубоко изучить личностные особенности и форму их проявления. Так же, этот метод помогает определить актуальность и методологическую основу исследования.

2) Психодиагностическое тестировани

Метод психодиагностического тестирования направлен на исследование личностных особенностей и психических качеств, при помощи использования психологических тестов. В нашем исследовании этот метод поможет определить 
доминирующие личностные особенности у студентов социономических и технических направление.

3) Математически-статистический метод обработки данных

Математико - статистический метод обработки данных был использован для обработки эмпирического тестирования с помощью t-критерия Стьюдента. В данном исследовании этот метод использовался для выявления средних значений и сравнительного анализа студентов социономических и технических направлений профессиональной подготовки.

Показатели экстраверсии / интроверсии и нейротизма (\%)

\begin{tabular}{|c|c|}
\hline Показатели & Результаты \\
\hline экстраверт & 20 \\
\hline слабо выраженная тенденция к экстраверсии & 35 \\
\hline слабо выраженная тенденция к интроверсии & 25 \\
\hline интроверт & 20 \\
\hline $\begin{array}{c}\text { высокий уровень нейротизма (выраженная } \\
\text { эмоциональная неустойчивость) }\end{array}$ & 10 \\
\hline Средний уровень нейротизма & 55 \\
\hline $\begin{array}{c}\text { Низкий уровень нейротизма(эмоциональная } \\
\text { устойчивость) }\end{array}$ & 35 \\
\hline
\end{tabular}

Таблийа 1

Результаты исследования темперамента(\%)

\begin{tabular}{|c|c|}
\hline Показатель & Результаты \\
\hline Меланхолик & 10 \\
\hline Флегматик & 5 \\
\hline Сангвиник & 50 \\
\hline Холерик & 35 \\
\hline
\end{tabular}

Таким образом, можно сделать вывод о том, что больше всего студентов социономического направления профессиональной подготовки обладают такими личностными особенностями как: экстраверсия, эмоциональная устойчивость, также преобладание типа темперамента-сангвиник. Для определения профессиональной направленности у студентов социономических направлений была предложена методика Л. Н. Кабардовой «Опросник профессиональной готовности».

Таблица 3

Проиенты выбора профессиональной направленности студентов(\%)

\begin{tabular}{|c|c|}
\hline Показатели & Результаты \\
\hline Человек-человек & 37 \\
\hline Человек-техника & 9 \\
\hline Человек-художественный образ & 22 \\
\hline Человек-знак & 14 \\
\hline Человек-природа & 18 \\
\hline
\end{tabular}

Итак, из всего выше сказанного, можно сделать вывод о том, что больше всего студенты социономических направлений профессиональной подготовки принадлежат к таким профессиональным направленностям как: человек-человек, человекхудожественный образ.

Для определения у студентов социономических направлений, самоактуализации и особенностей личности являющихся её компонентом использовалась методика Э. Шострома "Опросник диагностики самоактуализации личности САМОАЛ".

Показатели уровнясамоактуализачии и её компонентов(\%)

Таблицุа 4

\begin{tabular}{|c|c|c|c|}
\hline \multirow{2}{*}{ Показатель } & \multicolumn{3}{|c|}{ Уровни } \\
\cline { 2 - 4 } & Низкий & Средний & Высокий \\
\hline Самоактулизация & 5 & 90 & 5 \\
\hline Ориентация & 20 & 80 & 0 \\
\hline Ценности & 0 & 90 & 10 \\
\hline
\end{tabular}




\begin{tabular}{|c|c|c|c|}
\hline Взгляд на природу & 5 & 90 & 5 \\
\hline Потребность в познании & 5 & 95 & 0 \\
\hline Креативность & 5 & 95 & 0 \\
\hline Автономность & 5 & 95 & 15 \\
\hline Спонтанность & 0 & 85 & 0 \\
\hline Самопонимание & 10 & 90 & 10 \\
\hline Аутосимпатия & 10 & 80 & 20 \\
\hline Контактность & 10 & 70 & 85 \\
\hline Гибкость в общении & 0 & 15 & 0 \\
\hline
\end{tabular}

Таким образом, из всего выше сказанного, можно сделать вывод о том, что больше студенты социономических направления профессиональной подготовки в большинстве случаев обладают средним уровнем самоактуализации и особенностями личности такими как: ценности, ориентация во времени, ценности, потребность в познании, креативность, автономность, спонтанность, самопонимание, аутосимпатия, контакность.

Для диагностики личностных особенностей студентов технических направлений профессиональной подготовки были использованы методики на определение темперамента, уровня самоактуализации и профессиональной направленности. Для определения темперамента испытуемым был предложен для прохождения опросник «Личностный опросник Г. Айзенка»

Таблий 5

Показатели интроверсии-экстроверсии, эмоџиональной устойчивостинеустойчивости (\%)

\begin{tabular}{|c|c|}
\hline Показатель & Результаты \\
\hline экстраверт & 5 \\
\hline слабо выраженная тенденция к экстраверсии & 30 \\
\hline слабо выраженная тенденция к интроверсии & 50 \\
\hline интроверт & 0 \\
\hline высокий уровень нейротизма (выраженная эмоциональная \\
неустойчивость) & 30 \\
\hline Средний уровень нейротизма & 70 \\
\hline
\end{tabular}

Таблииа 6

Показатели типа темперамента у студентов(\%)

\begin{tabular}{|c|c|}
\hline Показатель & Результаты \\
\hline Меланхолик & 5 \\
\hline Флегматик & 50 \\
\hline Сангвиник & 30 \\
\hline Холерик & 15 \\
\hline
\end{tabular}

Таким образом, из всего выше сказанного, можно сделать вывод о том, что больше всего студентов технического направления профессиональной подготовки обладают такими личностными особенностями как: интроверсия, эмоциональная устойчивость, также преобладание типа темперамента - флегматик.

В дальнейшем для определения профессиональной направленности была предложена методика Л. Н. Кабардовой «Опросник профессиональной готовности».

Таблий 7

Проченты выбора профессиональной направленности студентов(\%)

\begin{tabular}{|c|c|}
\hline Показатели & Результаты \\
\hline Человек-человек & 23 \\
\hline Человек-техника & 28 \\
\hline Человек-художественный образ & 10 \\
\hline Человек-знак & 29 \\
\hline Человек-природа & 10 \\
\hline
\end{tabular}


Таким образом, из всего выше сказанного, можно сделать вывод о том, что больше всего студентов технического направления профессиональной подготовки принадлежат к таким профессиональным направленностям как: человек-техника, человек-знак.

В дальнейшем для определения самоактуализации и особенностей личности, являющихся её компонентом использовалась методика Э. Шострома "Опросник диагностики самоактуализации личности САМОАЛ".

Таким образом, из всего выше сказанного, можно сделать вывод о том, что больше всего студентов технического направления профессиональной подготовки принадлежат к таким профессиональным направленностям как: человек-техника, человек-знак.

В дальнейшем для определения самоактуализации и особенностей личности, являющихся её компонентом использовалась методика Э. Шострома "Опросник диагностики самоактуализации личности САМОАЛ".

Таблица 8

Показатели уровнясамоактуализации и её компонентов(\%)

\begin{tabular}{|c|c|c|c|}
\hline \multirow{2}{*}{ Показатель } & \multicolumn{3}{|c|}{ Уровни } \\
\cline { 2 - 4 } & Низкий & Средний & Высокий \\
\hline Самоактулизация & 5 & 95 & 0 \\
\hline Ориентация & 20 & 80 & 5 \\
\hline Ценности & 0 & 95 & 0 \\
\hline Взгляд на природу & 5 & 95 & 5 \\
\hline $\begin{array}{c}\text { Потребность в } \\
\text { познании }\end{array}$ & 10 & 85 & 0 \\
\hline Креативность & 5 & 95 & 0 \\
\hline Автономность & 0 & 100 & 0 \\
\hline Спонтанность & 5 & 85 & 5 \\
\hline Самопонимание & 10 & 90 & 15 \\
\hline Аутосимпатия & 10 & 85 & 5 \\
\hline Контактность & 15 & 70 & 85 \\
\hline Гибкость в общении & 10 & &
\end{tabular}

Таким образом, из всего выше сказанного, можно сделать вывод о том, что больше всего студентов технического направления профессиональной подготовки в большинстве случаев обладают средним уровнем самоактуализации и особенностями личности такими как:ориентация во времени, ценности, потребность в познании, креативность, автономность, спонтанность, самопонимание, аутосимпатия, контакность, гибкость в общении. Для сравнительного анализа темперамента, самоактуализации личности и профессиональной направленности студентов социономических и технических направлений с помощью программы Exelбылиспользованt-критерий Стьюдента.

С помощью данной математической статистики были получены средние значения. Результаты можно наблюдать в таблице 9, в таблице 10 и 11.

Таблица 9

Средние значения показателей экстраверсии / интроверсии и нейротизма

\begin{tabular}{|c|c|c|c|c|}
\hline \multirow[b]{2}{*}{ Показатель } & \multicolumn{2}{|c|}{ Среднее значение } & \multirow[b]{2}{*}{ t-эмпр. } & \multirow[b]{2}{*}{ t-критич. } \\
\hline & $\begin{array}{c}\text { Студенты технических } \\
\text { направлений }\end{array}$ & $\begin{array}{c}\text { Студенты } \\
\text { социономических } \\
\text { направленнй }\end{array}$ & & \\
\hline $\begin{array}{l}\text { Экстраверсия- } \\
\text { интроверсия }\end{array}$ & 10,3 & 11,9 & 5,7 & $\begin{array}{c}\text { Уровень } \\
\text { p>=0,01 } \\
2,86 \\
\end{array}$ \\
\hline Нейротизм & 8 & 11 & 7,2 & $\begin{array}{c}\text { Уровень } \\
\mathrm{p}>=0,01 \\
2,86\end{array}$ \\
\hline
\end{tabular}


$\mathrm{t}$-критическое $<\mathrm{t}$-эмпирическое, соответсвенно связь на уровне $\mathrm{p}=>0,01$ значима.

Полученные результаты позволяют нам сделать такие выводы, как:

1) Среди студентов социномических направлений профессиональной подготовки больше экстравертов, чем среди студентов технических направлений.

2) Студенты технических направлений профессиональной подготовки более эмоционально устойчивы, чем студенты социномических направлений.

Таблица 10

Среднее значение показателей самоактуализации и её компонентов

\begin{tabular}{|c|c|c|c|c|}
\hline \multirow[b]{2}{*}{ Показатель } & \multicolumn{2}{|c|}{ Среднее значение } & \multirow[b]{2}{*}{ t-эмп. } & \multirow[b]{2}{*}{ t-критич. } \\
\hline & $\begin{array}{c}\text { Студенты } \\
\text { технических } \\
\text { направлений }\end{array}$ & $\begin{array}{c}\text { Студенты } \\
\text { социономических } \\
\text { направлений }\end{array}$ & & \\
\hline Человек-человек & 31 & 42 & 5,6 & $\begin{array}{c}\text { Уровень } \\
\mathrm{p}>=0,01 \\
2,86\end{array}$ \\
\hline Человек-техника & 38 & 14 & 9,8 & $\begin{array}{c}\text { Уровень } \\
\mathrm{p}>=0,01 \\
2,86\end{array}$ \\
\hline Человек-природа & 13 & 15 & 6,9 & $\begin{array}{c}\text { Уровень } \\
\mathrm{p}>=0,01 \\
2,86\end{array}$ \\
\hline $\begin{array}{c}\text { Человек- } \\
\text { художественный } \\
\text { образ }\end{array}$ & 14 & 39 & 8,9 & $\begin{array}{c}\text { Уровень } \\
\mathrm{p}>=0,01 \\
2,86\end{array}$ \\
\hline Человек-знак & 39 & 13 & 4,6 & $\begin{array}{c}\text { Уровень } \\
\mathrm{p}>=0,01 \\
2,86\end{array}$ \\
\hline
\end{tabular}

$\mathrm{t}$-критическое $<\mathrm{t}$-эмпирическое, соответсвенно связь на уровне $\mathrm{p}=>0,01$ значима.

Полученные результаты в таблице 10 позволяют нам сделать такие выводы, как:

1) Студенты социономических направлений профессиональной подготовки более склонны к профессиональной направленности «Человек - человек», чем студенты технических направлений.

2) Студенты технических направлений профессиональной подготовки более склонны к профессиональной направленности «Человек-техника», чем студенты социономических направлений.

3) Студенты социономических направлений профессиональной подготовки более склонны к профессиональной направленности «Человек - природа», чем студенты технических направлений.

4) Студенты социономических направлений профессиональной подготовки более склонны к профессиональной направленности «Человек художественный образ», чем студенты технических направлений.

5) Студенты технических направлений профессиональной подготовки более склонны к профессиональной направленности «Человек-знак», чем студенты социономических направлений.

Таблица 11

Средние значение самоактуализации и её компонентов

\begin{tabular}{|c|c|c|c|c|}
\hline \multirow[b]{2}{*}{ Показатель } & \multicolumn{2}{|c|}{ Средние значение } & \multirow[b]{2}{*}{ t-эмп. } & \multirow[b]{2}{*}{ t-критич. } \\
\hline & $\begin{array}{c}\text { Студенты } \\
\text { социономических } \\
\text { направлений }\end{array}$ & $\begin{array}{c}\text { Студенты } \\
\text { технических } \\
\text { направлений } \\
\end{array}$ & & \\
\hline $\begin{array}{c}\text { Самоактуализ } \\
\text { ация }\end{array}$ & 47 & 46 & 9,0 & $\begin{array}{c}\text { Уровень } \mathrm{p}>= \\
0,01 \\
2,86 \\
\end{array}$ \\
\hline $\begin{array}{c}\text { Ориентация } \\
\text { во времени }\end{array}$ & 40 & 41 & 8,9 & $\begin{array}{c}\text { Уровень } \mathrm{p}>= \\
0,01 \\
2,86\end{array}$ \\
\hline
\end{tabular}




\begin{tabular}{|c|c|c|c|c|}
\hline Ценности & 58 & 57 & 8,9 & $\begin{array}{c}\text { Уровень } \mathrm{p}>= \\
0,01 \\
2,86\end{array}$ \\
\hline $\begin{array}{c}\text { Взгляд на } \\
\text { природу } \\
\text { человека }\end{array}$ & \multirow{2}{*}{43} & 42 & 9,0 & $\begin{array}{c}\text { Уровень } \mathrm{p}>= \\
0,01\end{array}$ \\
\hline $\begin{array}{c}\text { Потребность } \\
\text { в познании }\end{array}$ & 54 & 54 & 8,7 & $\begin{array}{c}\text { Уровень } \mathrm{p}>= \\
0,01 \\
2,86\end{array}$ \\
\hline Креативность & \multirow{2}{*}{56} & 50 & 7,6 & $\begin{array}{c}\text { Уровень } \mathrm{p}>= \\
0,01 \\
2,86\end{array}$ \\
\hline $\begin{array}{c}\text { Автономност } \\
\text { ь }\end{array}$ & \multirow{2}{*}{56} & 56 & 9,8 & $\begin{array}{c}\text { Уровень } \mathrm{p}>= \\
0,01 \\
2,86\end{array}$ \\
\hline
\end{tabular}

$\mathrm{t}$-критическое $<\mathrm{t}$-эмпирическое, соответсвенно связь на уровне $\mathrm{p}=>0,01$ значима.

Полученные результаты позволяют нам сделать такие выводы, как:

1) Студенты социномических направлений профессиональной подготовки более самоактуализированы, чем студенты технических направлений.

2) Студенты технических направлений профессиональной подготовки лучше ориентируются во времени, чем студенты социономических направлений.

3) У студентов социномических направлений профессиональной подготовки лучше развиты ценностные ориентации, чем у студентов технических направлений.

4) У студентов социномических направлений профессиональной подготовки лучше развит взгляд на природу человека, чем у студентов технических направлений.

5) У студентов социономических и технических направлений профессиональной подготовки одинаково развита потребность в познании.

6) У студентов социномических направлений профессиональной подготовки лучше развита креативность, чем у студентов технических направлений.

7) $\mathrm{y}$ студентов социономических и технических направлений профессиональной подготовки одинаково развита автономность.

8) У студентов технических направлений профессиональной подготовки в большей мере преобладает спонтанность, чем у студентов социономических направлений.

9) У студентов социономических и технических направлений профессиональной подготовки одинаково развито самопонимание.

10) У студентов социномических направлений профессиональной подготовки лучше развитааутосимпатия, чем у студентов технических направлений.

11) У студентов социномических направлений профессиональной подготовки лучше развита контактность, чем у студентов технических направлений.

12) У студентов социномических направлений профессиональной подготовки лучше развита контактность, чем у студентов технических направлений.

По результатам оценки средних показателей, было установлено, что полученное значение $\mathrm{t}$ (эмпирическое) находится в зоне значимости. Это означает, что между студентами технических и социономических направлений профессиональной подготовки есть различия в их личностных особенностях.

\section{Заключение}

В данной работе были рассмотрены личностные особенности и профессиональная направленность с позиции отечественных и зарубежных учёных.

Нами была сформирована и охарактеризована выборка, состоящая из 20 студентов высшего учебного заведения, учащихся на первом курсе бакалавриата. 
Были подобраны и проведены такие методики, как: Подростковый опросник (Г. Айзенка); Самоактуализационный тест (Э. Шостром); Методика определения профессиональной готовности (Л. Н. Кабордовой).

На основании результатов, полученных в ходе проведения подобранных методик, был проведён эмпирический анализ различий личностных особенностей у студентов социономических и технических направлений профессиональной подготовки. На основании этого были выявлены различия средних показателей индивидуальных особенностей. Анализ показал, что студенты социономических направлений профессиональной подготовки болле общительны, контактны, креативней. Студенты технических направлений профессиональной подготовки обладают более повышенной серьезностью и независимостью суждений.

Были выявлены значительные различия средних показателей личностных особенностей у студентов социономических и технических направлений профессиональной подготовки, в результате чего гипотеза была подтверждена.

$$
* * *
$$

1. Абульханова-Славская. К. А. Психология и сознание личности (проблемы методологии, теории и исследования реальной личности): избранные психололгические труды [Текст] / К. А. АбульхановаСлавская. - Москва. - МПСИ, 2000. - С. 72-73.

2. Андерсонс. Г. В. Концептуальное обоснование содержания педагогической поддержки старшеклассников в выборе будущей профессий[Текст] / Г. В. Андерсон. Воронеж: ВГПУ. - 2006. $35 \mathrm{c}$.

3. Бордаченко. С. И. Профессиональная подготовка студентов гуманитарного вуза в области математики дис. канд. пед. наук [Текст] / С. И. Бордаченко. - Сходня, 2003. - 60 с.

4. Егоров. И. В. Динамика взаимосвязи самооценки и социально-психологических качеств личности студентов педагогического вуза [Электронный ресурс] / И. В. Егоров. - Режим доступа: http://www.dslib.net/soc-psixologia/dinamika-vzaimosvjazi-samoocenki-i-socialno-psihologicheskihkachestv-lichnosti.html. Дата обращения: 20. 122017.

5. Куликов. Л. ВПсихология личности в трудах отечественных психологов[Текст] / Л. В. Куликов. Питер, 2005. -48 с.

\section{Усманов Р.Ф. \\ Организационные аспекты разрешения конфликта интересов в органах внутренних дел Российской Федерации}

Академия управления МВД России

(Россия, Москва)

doi 10.18411/spc-04-03-2018-30

idsp 000001:spc-04-03-2018-30

Разрешение конфликта интересов в органах внутренних дел Российской Федерации представляет собой нормативно закрепленную и организационно обеспеченную процедуру, позволяющую идентифицировать (выявлять) состояние конфликта интересов (мнимый или реальный конфликт); анализировать содержание конфликта интересов (источники или причины конфликта интересов индивидуальные, организационные; цели, ценности, мотивы носителей конфликта); осуществлять поиск, установление, реализацию организационных средств и методов его разрешения.Разрешение конфликта интересов должно основываться на единых методологических подходах, а также на использовании комбинированных средств и методов; ориентироваться на реализацию преимущественно не карательных, а предупредительных мер; способствовать достижению баланса публичных и частных интересов на правоохранительной службе, созданию благоприятных правовых и организационных условий невыгодности интересов и игнорирования интересов службы, как для служащего (коллектива), так и организации вступления в конфликт.

Основой разрешения организационного конфликта является отведение противоречивых функций по различным должностным лицам, отделам или ведомствам. Принцип недопустимости совмещения бюрократической и государственно- 